\title{
Post Traumatic Pneumocephalus- Clinical Profile in a Tertiary Care Centre
}

\author{
Authors \\ Dr C.V.Rajendran ${ }^{1}$, Dr Nowshad.M*, Dr Anoop Parameswaran ${ }^{3}$, \\ Dr Muhammed Rasheem.P ${ }^{\mathbf{4}}$, Dr Muhammed Sameer.P.T \\ ${ }^{1}$ Additional professor, Department of Surgery, Government Medical College, Trivandrum \\ ${ }^{2}$ Associate Professor, Surgery, Travancore Medical College, Kollam \\ ${ }^{3}$ Consultant Neurosurgeon, Aster Medicity \\ ${ }^{4,5}$ Junior resident, Government Medical College, Trivandrum \\ *Corresponding Author
}

Dr Nowshad.M

Associate Professor, Surgery, Travancore Medical College, Kollam

\begin{abstract}
Introduction: The burden of head injury due to RTA on the society has now become a major cause of concern. The other main etiological factors contributing to head injuries include alcohol consumption, assault, fall from height and workplace injuries. Patients with suspected head injury are categorized using GCS. A good number of patients admitted with head injury suffer from CSF leak and pneumocephalus. There is a dearth of studies exploring the outcomes in patients with Post-Traumatic pneumocephalus in our setting. The objective of this study was to explore the various outcomes and management of patients suffering from Post-Traumatic pneumocephalus.

Materials and Methods: Fifty consecutive patients with closed head injuries admitted in the surgical wards and neurosurgical wards in 2007 were recruited into this study with written informed consent from the patients or from the bystanders. Various parameters, including baseline demographic features, details of RAT, presence or absence of vomiting, loss of consciousness, ENT bleeding, GCS scores, early and late CSF rhinorrhea, head ache, meningitis, anemia, cranial nerve nerve injuries, details of surgery and CT findings, brain injury and fractures were collected in a standardized pretested data collection form. All data were analysed using $R$ statistical package.

Results: The mean age of these 50 study participants was $47.3 \pm 16.7$ with a male predominance. Road traffic accidents were the major etiological factor(94\%). Frontal sinus fracture was present in 36\%. Early CSF rhinorrhea occurred in $12 \%$ of patients and delayed in $18 \%$ of patients. Pneumocephalus was present in 58\% of patients. First ct showed pneumocephalus in $90 \%$ of patients. However, in second ct it came down to 20 percent. Majority of patients (84\%) required only conservative management. Surgical intervention was resorted to in the remaining $16 \%$ of cases.

Discussion: In our study, surgery was the treatment modality in $16 \%$ of individuals. Most of them presented with features of delayed and continuous CSF leak not responding to conservative management. Most of them underwent a duroplasty with fascia lata or G-patch. Surgery was associated with a very good outcome. Patients were followed up sequentially for any residual focal neurological deficits or cranial nerve abnormalities. All were detected to be symptom free. One interesting thing to be noted was the incidence of frontal sinus fractures. Incidence of frontal sinus fractures in our study was found to be $36 \%$.
\end{abstract}




\section{Introduction}

Head injury due to road traffic accidents has now become a major public health problem ${ }^{1,2}$. Alcohol, assault, fall from height and accident at work places are the other major contributory factors to the increasing incidence of head injuries ${ }^{1,3,4}$. This is now becoming a grave problem as it involves mainly the adolescents and young adults. The cost to the individual in terms of pain, suffering, incapacitation, disfigurement, permanent disability and loss of self esteem is unremarkable ${ }^{5}$. When a patient is bought to the casualty with suspected head injury, a careful physical examination is done, which includes the vital signs, neurological and other systems. Glasgow Coma Scale (GCS) is a universally accepted method for categorizing a patient with suspected head injury. Other scoring systems are also available like Revised Trauma Scale, Injury Severity Score etc ${ }^{6-8}$.

CT Scan which is considered as the gold standard is taken depending on the clinical condition of the patient. Repeat CT scan may be required if the patient fails to improve or deteriorates ${ }^{9-12}$.

A good number of patients admitted with head injury suffer from CSF leak and pneumocephalus ${ }^{13-15}$. Other injuries encountered are facial bone fractures, base of skull and temporal bone fractures, intraparenchymal or intracranial hemorrhages. There were also reasonable number of patients showing development of delayed CSF leak. Complications to be looked for include meningitis, abnormalities of cranial nerves. Management is mainly conservative with adequate antibiotics and necessary surgical intervention at appropriate time ${ }^{16,17}$.

In this study, we aimed to explore various outcomes and management of patients suffering from Post-Traumatic pneumocephalus.

\section{Materials and Methods}

Fifty cases of head injuries admitted in the surgical wards and neurosurgical intensive care units during the period from Jan 2007 - October 2007 were studied. Informed consents were taken from all patients. Strict confidentialities of the patients were maintained during different phases of the study.

All consecutive patients with closed head injuries were included in the study. In addition patients with initial CT features of pneumocephalus and immediate or delayed CSF were also recruited. We excluded patients with open head injuries.

Condition of the patient at admission, including vital signs, GCS score, other co-morbid conditions and injuries were recorded. A detailed neurological and other system examination were done and recorded. Findings of first CT usually taken at the time of admission were recorded. Patients were assessed for features of CSF leak such as persistent nasal discharge, a salty taste and dripping in the back of the throat, fullness in the ear accompanied by some degree of hearing loss. They were also assessed for cranial nerve injuries such as anosmia, ocular muscle palsies, facial nerve palsy, etc. Repeat CT scan was taken depending on the condition of the patient. They were also followed up to know if they had developed features of delayed CSF leak such as CSF Rhinorrhoea or Otorrhoea and cranial nerve abnormalities. All CT scans were assessed to know the presence or absence of fractures of frontal sinus.

After discharge and on further regular visits, they were assessed to see if they had features of persistent/new onset CSF leak \& Cranial nerve abnormalities.

Apart from baseline demographic variables, details of RAT, presence or absence of vomiting, loss of consciousness, ENT bleeding, GCS scores, early and late CSF rhinorrhea, headache, meningitis, anemia, cranial nerve nerve injuries, details of surgery and CT findings, brain injury and fractures were defined with working definitions and information collected in a standardized pretested data collection form.

Data were analysed using $\mathrm{R}$ statistical package. Continuous data was expressed as mean and standard deviation and categorical data as frequency and percentages. To elucidate the associations and comparisons between different parameters, Chi-square test was used. For all 
statistical evaluations, a two-tailed probability of value $<0.05$ were considered significant.

\section{Results}

In this study, comprising of 50 patients, the majority of cases occurred in the age group of 3050 years with mean $(\mathrm{SD})$ being $47.3 \pm 16.7 \pm 16.7$. A major proportion of cases occurred in the male popu!ation (90\%). Road traffic accidents were a major aetiological factor in most of the cases, frequency was $94 \%$ compared to others which included assaults, fall etc.

Frequency of fracture of frontal sinus was $36 \%$. Frequency of CSF rhinorrhea both early and delayed was tabulated. Patients presenting with features of CSF leak within one week of head injury were classified as early and those after one week as delayed. Early CSF rhinorrhea occurred in $12 \%$ of individuals, and delayed CSF rhinorrhea occurred in $18 \%$ of individuals. Headache was a major complaint in $18 \%$ of individuals. Frequency of anosmia was $2 \%$. Other cranial nerve injuries like facial nerve injuries,
Vth nerve palsies, etc. occurred in $10 \%$ of individuals. Pneumocephalus with intra cerebral/intra parenchymal injuries occurred in $58 \%$ of patients. Meningitis occurred in $2 \%$ of individuals.

Frequency of pneumocephalus in 1st CT scan was $90 \%$ and that in 2nd, CT scan was 20\%. 2nd CT scan was taken within 24 hours of the 1 st CT scan. Majority of cases were treated conservatively $(84 \%)$. Surgery was opted for in $16 \%$ of cases. Mortality rate was $8 \%$.

We studied the association between management and associated injuries (Table1).In In all cases of delayed CSF rhinorrhea surgery was the modality of treatment opted; this was found to be significant $(p<0.001)$. In $62.5 \%$ of cases of early CSF rhinorrhea, surgery was the treatment of choice making this association significant $(p<0.001)$. Surgery was done in $62.5 \%$ of cases who had headache as the chief complaint $(p<0.001)$. Surgery was done in $50 \%$ of fractures of frontal sinus $(\mathrm{p}>0.05)$.

Table 1: comparison of patient's characteristics by management.

\begin{tabular}{|c|c|c|c|c|}
\hline & [ALL] $\mathrm{N}=50$ & surgery $\mathrm{N}=42$ & Conservative $\mathrm{N}=8$ & p.overall \\
\hline Age & $47.3(16.7)$ & $50.1(16.4)$ & $32.8(9.91)$ & 0.001 \\
\hline Sex: & & & & 0.176 \\
\hline Male & $45(90.0 \%)$ & $39(92.9 \%)$ & $6(75.0 \%)$ & \\
\hline Female & $5(10.0 \%)$ & $3(7.14 \%)$ & $2(25.0 \%)$ & \\
\hline RTA: & & & & 0.414 \\
\hline Absent & $3(6.00 \%)$ & $2(4.76 \%)$ & $1(12.5 \%)$ & \\
\hline Present & $47(94.0 \%)$ & $40(95.2 \%)$ & $7(87.5 \%)$ & \\
\hline Vomiting: & & & & 1.000 \\
\hline Absent & $7(14.0 \%)$ & $6(14.3 \%)$ & $1(12.5 \%)$ & \\
\hline Present & $43(86.0 \%)$ & $36(85.7 \%)$ & $7(87.5 \%)$ & \\
\hline LOC: & & & & 0.414 \\
\hline Absent & $3(6.00 \%)$ & $2(4.76 \%)$ & $1(12.5 \%)$ & \\
\hline Present & $47(94.0 \%)$ & $40(95.2 \%)$ & $7(87.5 \%)$ & \\
\hline ENT bleed: & & & & 0.310 \\
\hline Absent & $7(14.0 \%)$ & $5(11.9 \%)$ & $2(25.0 \%)$ & \\
\hline Present & $43(86.0 \%)$ & $37(88.1 \%)$ & $6(75.0 \%)$ & \\
\hline GCS: & & & & 0.670 \\
\hline 3 & $3(6.00 \%)$ & $3(7.14 \%)$ & $0(0.00 \%)$ & \\
\hline 14 & $3(6.00 \%)$ & $2(4.76 \%)$ & $1(12.5 \%)$ & \\
\hline 15 & $44(88.0 \%)$ & $37(88.1 \%)$ & $7(87.5 \%)$ & \\
\hline CSF rhinorrhea Early: & & & & $<0.001$ \\
\hline Absent & $44(88.0 \%)$ & $41(97.6 \%)$ & $3(37.5 \%)$ & \\
\hline present & $6(12.0 \%)$ & $1(2.38 \%)$ & $5(62.5 \%)$ & \\
\hline CSE Rhinorrhea Delayed: & & & & $<0.001$ \\
\hline Absent & $41(82.0 \%)$ & $41(97.6 \%)$ & $0(0.00 \%)$ & \\
\hline Present & $9(18.0 \%)$ & $1(2.38 \%)$ & $8(100 \%)$ & \\
\hline Headache: & & & & 0.003 \\
\hline
\end{tabular}




\begin{tabular}{|c|c|c|c|c|}
\hline Absent & $41(82.0 \%)$ & $38(90.5 \%)$ & $3(37.5 \%)$ & \\
\hline Present & $9(18.0 \%)$ & $4(9.52 \%)$ & $5(62.5 \%)$ & \\
\hline Fracture frontal: & & & & 0.436 \\
\hline Absent & $32(64.0 \%)$ & $28(66.7 \%)$ & $4(50.0 \%)$ & \\
\hline Present & $18(36.0 \%)$ & $14(33.3 \%)$ & $4(50.0 \%)$ & \\
\hline Meningitis: & & & & 1.000 \\
\hline Absent & $49(98.0 \%)$ & $41(97.6 \%)$ & $8(100 \%)$ & \\
\hline Absent & $1(2.00 \%)$ & $1(2.38 \%)$ & $0(0.00 \%)$ & \\
\hline Anosmia: & & & & 0.160 \\
\hline Absent & $49(98.0 \%)$ & $42(100 \%)$ & $7(87.5 \%)$ & \\
\hline Present & $1(2.00 \%)$ & $0(0.00 \%)$ & $1(12.5 \%)$ & \\
\hline Cranial nerve injuries: & & & & 0.577 \\
\hline Absent & $45(90.0 \%)$ & $37(88.1 \%)$ & $8(100 \%)$ & \\
\hline Present & $5(10.0 \%)$ & $5(11.9 \%)$ & $0(0.00 \%)$ & \\
\hline CT1 pneumocephalus.: & & & & 0.577 \\
\hline Absent & $5(10.0 \%)$ & $5(11.9 \%)$ & $0(0.00 \%)$ & \\
\hline Present & $45(90.0 \%)$ & $37(88.1 \%)$ & $8(100 \%)$ & \\
\hline CT 2 pneumocephalus.: & & & & 0.005 \\
\hline Absent & $40(80.0 \%)$ & $37(88.1 \%)$ & $3(37.5 \%)$ & \\
\hline Present & $10(20.0 \%)$ & $5(11.9 \%)$ & $5(62.5 \%)$ & \\
\hline Other Fracture: & & & & 0.050 \\
\hline Absent & $24(48.0 \%)$ & $23(54.8 \%)$ & $1(12.5 \%)$ & \\
\hline Present & $26(52.0 \%)$ & $19(45.2 \%)$ & $7(87.5 \%)$ & \\
\hline Brain Injury.: & & & & 0.007 \\
\hline Absent & $21(42.0 \%)$ & $14(33.3 \%)$ & $7(87.5 \%)$ & \\
\hline Present & $29(58.0 \%)$ & $28(66.7 \%)$ & $1(12.5 \%)$ & \\
\hline Mortality.: & & & & 1.000 \\
\hline Absent & $46(92.0 \%)$ & $38(90.5 \%)$ & $8(100 \%)$ & \\
\hline Present & $4(8.00 \%)$ & $4(9.52 \%)$ & $0(0.00 \%)$ & \\
\hline
\end{tabular}

In $62.5 \%$ of cases where pneumocephalus was present in 2nd CT scan, surgery was adopted $(\mathrm{p}<0.01)$. Surgery was also the mode of treatment when pneumocephalus was associated with other fractures $(\mathrm{p}<0.05)$ and evidence of parenchymal injury $(\mathrm{P}<0.01)$ (figure1)

Figure 1: Comparison of management by pneumocephalus

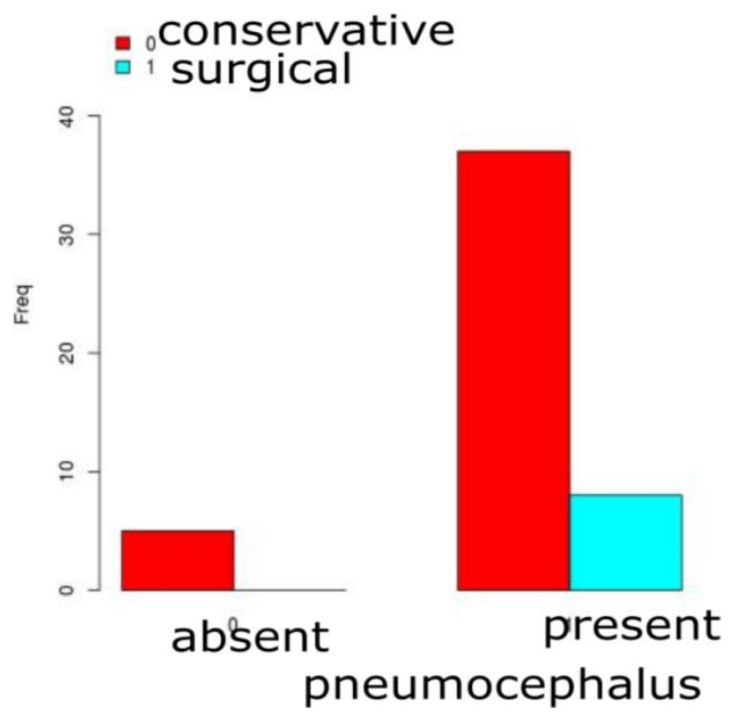

All patients who underwent surgery, the mortality rate was nil. Of those patients who were subjected to conservative mode of management; mortality rate was $9.50 \%$ ( $>>0.05)$. It was observed that the outcome was poor when the Glasgow Coma Scale was less than 14.

Meningitis had a negative impact upon the outcome of patients suffering from intracranial pneumocephalus $(\mathrm{p}<0.05)$. Presence of pneumocephalus in 2nd CT scan had a direct association with mortality $(p<0.001)$. Presence of other fractures such as temporal bone fractures, orbital fractures, etc. and presence of intracranial parenchymal injuries all added to the increased mortality rate $(\mathrm{p}<0.05)$.

\section{Discussion}

In this study, we aimed to elaborate the outcome of patients in our Institute suffering from PostTraumatic pneumocephalus.

Majority of cases of pneumocephalus were following road traffic accidents. Most of them were in the age group between 30 and 50 years. The prevalence of CSF rhinorrhea, both early and 
delayed, was $30 \%$. The The prevalence of fracture of frontal sinus was $36 \%$. The The prevalence of meningitis was 4\%.Majority Majority of the patients were managed conservatively. Surgery was the modality of treatment in $16 \%$ of individuals. The prognosis after surgery was excellent.

According to a study conducted by W-I Steudel \& H-Hacker at the Department of Neurosurgery, Frankfurt, the incidence of pneumocephalus was $9.7 \%{ }^{18}$. Pneumocephalus was detected in 40 out of $49(82 \%)$ of head injury patients within 6 hours of accident. Injuries associated with a pneumatocele or a single air bubble had a good prognosis, as do frontobasal lesions. It is well known that head injury patients with CT findings of multiple air bubbles portend a poor prognosis, and it points towards apossible frontal or anterodorsal fracture. An emergency craniotomy is indicated if there is a space occupying finding caused by extracerebral hematoma or pneumocephalus associated with depressed skull fractures. Cases with aerocele and pneumocephalus suggest a probable communication to the exterior ${ }^{19}$. These findings can present even years after.

Incidence of CSF Rhinorrhoea was found to be $30 \%$. This included both early and late. Early CSF Rhinorrhoea included those that presented within one week of the head injury, and late CSF Rhinorrhoea included those that presented after one week of the head injury. In a study conducted at the Royal Adelaide Hospital, Australia, of the 41 cases of traumatic intracranial aerocele studied; almost half of them had been coexisting with CSF rhinorrhea. In this series, skull base fractures were associated with CSF leakage. Moreover, majority of the leaks subsided with conservative measures. However patients with persistent CSF leaks were at increased risk for meningitis, and many patients underwent surgical intervention. Jonathan A. Friedman and Michael J.Ebersold at the Department of Neurosurgery, Mayo Clinic, Minnesota conducted a study of 51 patients treated between 1994 and 1998; with CSF leaks that persisted for 24 hours or longer after head injury ${ }^{20}$. In this study, 28 patients $(53 \%)$ had spontaneous resolution of the leakage of five days. In twenty three patients (47\%) craniotomy was done. Eight patients (16\%) had delayed leaks at an average of 13-day post trauma. They reported that even under antibiotic prophylaxis, there was a $10 \%$ prevalence of meningitis in those with clinically proven CSF leakage.

Prophylactic Antibiotics were started on the day of admission or as soon as an evidence of pneumocephalus was detected. Even with the inclusion of prophylactic Antibiotics in the treatment regime; the incidence of meningitis was $4 \%$ in our study. However, this had some other confounding factors too like multiple facial bone fractures; temporal bone fractures, associated intraparenchymal injury, etc. Studies conducted at Mayo Clinic, Minnesota and Manshad University, Iran and similar studies proved that the use of prophylactic antibiotics reduced the incidence of meningitis to half of the actual value ${ }^{21-23}$.

Another interesting thing to be noted was the incidence of frontal sinus fractures. Incidence of frontal sinus fractures in our study was found to be $36 \%$. Studies conducted by Brisman, Linn M. Quant and Park et al. have described that in patients with CSF leaks associated with skull fractures, the most commonly involved was a frontal sinus fracture ${ }^{24,25}$.

Michael Briggs et al. at The Radcliffe Infirmary, Oxford studied the presentation and management of 33 patients with traumatic pneumocephalus and recognized two groups ${ }^{26}$. The first consists of 12 patients who developed an intracerebral aerocele, the onset of which was delayed for up to 52 days from the time of injury. Emergency craniotomy was resorted to in this group. In the second group, the air was present in the subarachnoid space or subdural space. They observed that in those patients with conservative management was preferred needed to be covered with early antibiotics prophylaxis. In our study, surgery was the treatment modality in $16 \%$ of individuals. Most of them presented with features of delayed and continuous CSF leak not responding to conservative management. Most of them 
underwent a duroplasty with fascia lata or Gpatch. Surgery was associated with a very good outcome. Patients were followed up sequentially for any residual focal neurological deficits or cranial nerve abnormalities. All were detected to be symptom free.

\section{Reference}

1. Consumption WECoPRtA, Organization WH. Problems related to alcohol consumption: report of a WHO expert committee [meeting held in Geneva from 20 to 26 November 1979]. 1980.

2. Christoffel $\mathrm{T}$, Gallagher S. Injury prevention and public health: practical knowledge, skills, and strategies: Jones \& Bartlett Learning; 2006.

3. Mackay M. The increasing importance of the biomechanics of impact trauma. Sadhana 2007; 32(4): 397-408.

4. Pratt OE, Tucker MM. Approaches to the alcohol problem in the workplace. Alcohol and Alcoholism 1989; 24(5): 453-64.

5. Morgado FL, Rossi LA. Correlação entre a escala de coma de Glasgow e os achados de imagem de tomografia computadorizada em pacientes vítimas de traumatismo cranioencefálico. Radiologia Brasileira 2011; 44: 35-41.

6. Marion DW, Carlier PM. Problems with initial Glasgow Coma Scale assessment caused by prehospital treatment of patients with head injuries: results of a national survey. Journal of Trauma and Acute Care Surgery 1994; 36(1): 89-95.

7. Rowley G, Fielding K. Reliability and accuracy of the Glasgow Coma Scale with experienced and inexperienced users. The Lancet 1991; 337(8740): 535-8.

8. Doyle DJ. Glasgow Coma Scale (GCS). Computer Programs in Clinical and Laboratory Medicine: Springer; 1989: 113-6.

9. Stein SC, Ross SE. Mild head injury: a plea for routine early CT scanning. Journal of Trauma and Acute Care Surgery 1992; 33(1): 11-3.

10. Marshall LF, Marshall SB, Klauber MR, et al. A new classification of head injury based on computerized tomography. Special Supplements 1991; 75(1S): S14S20.

11. Kakarieka A, Braakman R, Schakel E. Clinical significance of the finding of subarachnoid blood on CT scan after head injury. Acta neurochirurgica 1994; 129(1): 1-5.

12. Toyama Y, Kobayashi T, Nishiyama Y, Satoh K, Ohkawa M, Seki K. CT for acute stage of closed head injury. Radiation medicine 2005; 23(5): 309-16.

13. Liao K-H, Wang J-Y, Lin H-W, et al. Risk of death in patients with post-traumatic cerebrospinal fluid leakage-Analysis of 1773 cases. Journal of the Chinese Medical Association 2016; 79: 58-64.

14. Kim YD, Lee JH, Cheong YK. Pneumocephalus in a Patient with No Cerebrospinal Fluid Leakage after Lumbar Epidural Block - A Case Report -. The Korean Journal of Pain 2012; 25: 262-6.

15. Kumar R, Mahapatra AK. Textbook of Traumatic Brain Injury: JP Medical Ltd; 2012.

16. Zeme S, Gerbino G, Benech F, et al. Decision making in frontobasal injuries. Quality management in head injuries care Eds L Gonzales- Feria, KRH von Wild, HE Diemath Servicio Canario de Salud 2000: 83-91.

17. Prosser JD, Vender JR, Solares CA. Traumatic cerebrospinal fluid leaks. Otolaryngologic Clinics of North America 2011; 44(4): 857-73.

18. Steudel W-I, Hacker H. Prognosis, incidence and management of acute traumatic intracranial pneumocephalus. Acta neurochirurgica 1986; 80(3): 93-9.

19. North J. On the importance of intracranial air. British Journal of Surgery 1971; 58 (11): 826-9. 
20. Friedman JA, Ebersold MJ, Quast LM.

Persistent posttraumatic cerebrospinal fluid leakage. Neurosurg Focus 2000; 9(1): e1.

21. Ratilal B, Costa J, Sampaio C. Antibiotic prophylaxis for preventing meningitis in patients with basilar skull fractures. Cochrane Database Syst Rev 2006; 1.

22. Askarian M, Moravveji AR, Assadian O. Prescription of prophylactic antibiotics for neurosurgical procedures in teaching hospitals in Iran. American journal of infection control 2007; 35(4): 260-2.

23. Eftekhar B, Ghodsi M, Nejat F, Ketabchi E, Esmaeeli B. Prophylactic administration of ceftriaxone for the prevention of meningitis after traumatic pneumocephalus: results of a clinical trial. Journal of neurosurgery 2004; 101(5): 757-61.

24. Brisman R, Hughes JE, Mount LA. Cerebrospinal fluid rhinorrhea. Archives of neurology 1970; 22(3): 245-52.

25. Park J-I, Strelzow VV, Friedman WH. Current management of cerebrospinal fluid rhinorrhea. The Laryngoscope 1983; 93(10): 1294-300.

26. Briggs M. Traumatic pneumocephalus. British Journal of Surgery 1974; 61(4): 307-12. 